\title{
Desafios do planejamento municipal de saneamento básico em municípios de pequeno porte: a percepção dos gestores
}

\section{Challenges of municipal planning for basic sanitation in small size municipalities: the managers' perception}

\author{
Severina Sarah Lisboa \\ Geógrafa. Doutora em Saneamento, Meio Ambiente e Recursos Hídricos pela Universidade Federal de Minas Gerais (UFMG) - Belo Horizonte (MG), Brasil.
}

Léo Heller

Engenheiro Civil. Mestre em Engenharia Sanitária. Doutor em Epidemiologia. Professor do Departamento de Engenharia Sanitária e Ambiental da UFMG - Belo Horizonte (MG), Brasil.

\section{Rogério Braga Silveira}

Doutor em Saneamento, Meio Ambiente e Recursos Hídricos da UFMG - Belo Horizonte (MG), Brasil.

\begin{abstract}
Resumo
A Lei no 11.445/2007 estabelece diretrizes para o saneamento básico no Brasil, apresentando, dentre outros direcionamentos, o planejamento como aspecto fundamental da gestão dos serviços. Buscando contribuir para a discussão, o presente trabalho identifica os principais fatores que dificultam esse processo de planejamento em nível municipal, sobretudo em municípios de menor porte, e os aspectos que motivam a elaboração do plano. O trabalho utiliza metodologia qualitativa de coleta e análise de dados, com realização de entrevistas semiestruturadas com gestores de 15 municípios localizados na Zona da Mata de Minas Gerais, e emprega a técnica de Discurso do Sujeito Coletivo para analisar as informações obtidas. As principais dificuldades identificadas são a indisponibilidade de recursos financeiros e a limitação quanto à qualificação profissional e capacidade técnica municipal. No entanto, ao vencer o primeiro obstáculo, a qualificação profissional pode ser parcialmente resolvida mediante realização de capacitação e contratação de profissionais, o que pode igualmente superar as dificuldades metodológicas. Questões como integração de órgãos das áreas que compõem o saneamento, vontade política e outros fatores também foram apontadas como obstáculos ao planejamento. Apesar das dificuldades, a elaboração dos planos é vista com otimismo e significativa motivação, percebendo-se que estes possivelmente não teriam seu desenvolvimento conduzido apenas pela motivação do cumprimento à demanda da legislação e sim pela convicção dos seus reais benefícios.
\end{abstract}

Palavras-chave: saneamento; planejamento; plano municipal de saneamento.

\begin{abstract}
The Law $n^{\circ}$ 11.445/2007 establishes guidelines for basic sanitation in Brazil, pointing the planning as a fundamental aspect of services management, among other enforcements. Aiming at contributing to this discussion, this article intends to identify the main factors that challenge the planning process at the municipal level, especially in small size municipalities, and the aspects that motivate the development of the plan. The study uses qualitative methodology to collect and analyze the data, conducting semi-structured interviews with managers of 15 municipalities located in the Zona da Mata of Minas Gerais, and applies the technique of the Collective Subject Discourse as analytical tool. The main difficulties identified are unavailability of financial resources and limitation regarding professional qualifications and municipal expertise. However, after overcoming the first obstacle, the qualification problem can be partially solved by training and contracting professionals, which can also lead to overcoming the methodological difficulties. Issues such as sector integration of areas that encompass the basic sanitation structure, political will and other factors were also identified as barriers to planning. Despite the difficulties, planning is seen with optimism and significant motivation, and one can realize that the fulfilment of the law could not be the main driver for the managers, but strongly their conviction of the real benefits.
\end{abstract}

Keywords: water and sanitation; planning; water and sanitation municipal planning 


\section{Introdução}

Os serviços de saneamento básico são essenciais para a promoção da saúde pública. A disponibilidade de água em quantidade e qualidade adequadas constitui fator de prevenção de doenças; a água em quantidade insuficiente ou qualidade imprópria para consumo humano poderá ser causadora de doenças. O mesmo pode ser verificado quanto à inexistência e pouca efetividade dos serviços de esgotamento sanitário, limpeza pública e manejo de resíduos sólidos e de drenagem urbana.

Muitos problemas de saúde ambiental na América Latina e Caribe são causados, dentre outros fatores, por deficiências de saneamento e exigências crescentes de proteção ambiental, agravadas pela intensificação da urbanização (BRASIL, 2004; RIBEIRO, 2004). Essa realidade pode ser comprovada analisando-se os quadros de morbidade e mortalidade relacionados a doenças de transmissão feco-oral (CLASEN \& CAIRNCROSS, 2004). A população dos países subdesenvolvidos está particularmente exposta aos riscos ambientais como inadequadas condições sanitárias (EZZATI et al., 2005). A realidade brasileira também sofre com deficiências nos serviços de saneamento, que se manifestam principalmente em escala municipal, afetando diretamente a população. $\mathrm{O}$ crescimento econômico brasileiro segue um modelo gerador de concentração de renda e infraestrutura, excluindo expressivos segmentos sociais de um nível de qualidade ambiental satisfatório, levando a ocorrência de doenças infecto-parasitárias onde se concentram as populações mais pobres, que sofrem com precárias condições sanitárias e ambientais. No país, verifica-se a coexistência de doenças infectocontagiosas e crônico-degenerativas (RIBEIRO, 2004).

Diante dessas deficiências do saneamento, torna-se necessário intervir na defesa do ambiente, promoção da saúde pública e melhoria das condições sanitárias, com especial ênfase para as áreas urbanas, onde se concentra majoritariamente a população brasileira. Verifica-se a necessidade de implementar o planejamento municipal do saneamento, buscando a melhoria do atendimento dos serviços visto que o planejamento urbano nem sempre incorpora este setor em toda a sua complexidade (BRASIL, 2006). A elaboração do Plano Municipal de Saneamento Básico passou a ser uma exigência legal, motivada pelo atendimento ao disposto na Lei $n^{\circ} 11.445$ de 2007, que estabelece diretrizes nacionais para o setor, nas quais a gestão dos serviços passa a ser obrigatoriamente direcionada pelo instrumento de planejamento que deve considerar um amplo horizonte de tempo.

O planejamento vem sendo utilizado pelos governos a fim de minimizar os custos sociais advindos da atuação das forças de mercado, propiciando melhoria da qualidade de vida da população (FRIEDMANN, 1987; KLOSTERMAN, 2003), auxiliando os gestores a assumir uma postura oposta à de improvisação (HUERTAS, 1996) e permitindo lidar com as incertezas da realidade futura, para vencer a passividade com ações pré e proativas para alcançar o futuro desejado (GODET \& DURANCE, 2009). Neste sentido, busca-se trabalhar com as possibilidades de futuro sem adotar uma visão determinista (SCHWARTZ, 1996), uma vez que não é possível controlar as forças sociais e econômicas (FRIEDMANN, 1992).
A gestão dos serviços pode atuar potencializando ou restringindo os benefícios do saneamento (HELLER \& NASCIMENTO, 2005). A organização e o planejamento das ações potencializam a gestão dos serviços públicos (YÉVENES-SUBIATRE, 2010), propiciando melhorias para a população, corrigindo problemas imediatos com ações de curto prazo, direcionando o futuro do setor a partir de ações de médio e longo prazo, além de reduzir improvisações e decisões emergenciais.

O Plano Nacional de Saneamento (PLANASA), elaborado na década de 1970, foi o primeiro plano brasileiro do setor que ampliou a oferta de serviços de abastecimento de água e esgotamento sanitário. Nas experiências mais recentes de planejamento em âmbito municipal, identificam-se planos mais integrados que consideram os quatro componentes do saneamento, dentre os quais estão os de Alagoinhas (BA), Belo Horizonte (MG), Guaíba (RS), Jaboticabal (SP), Porto Alegre (RS), Santo André (SP) e Vitória da Conquista (BA) (LIMA NETO \& SANTOS, 2012). O planejamento municipal do saneamento pode contribuir para a valorização, proteção e gestão equilibrada dos recursos naturais - particularmente dos recursos hídricos —, além de melhorar a eficiência dos serviços, a qualidade de vida e saúde da população e ampliar o acesso da população menos favorecida.

A Lei $n^{\circ}$ 11.445/2007 aponta o planejamento a partir da elaboração dos planos de saneamento básico dos quais dependem a validade dos contratos de prestação de serviços, os planos de investimentos e projetos dos prestadores, a atuação da entidade reguladora e fiscalizadora, a alocação de recursos públicos federais e os financiamentos com recursos da União ou geridos por órgãos ou entidades da União (GALVÃO JÚNIOR et al., 2012). A demanda pelo planejamento tem aberto novas perspectivas para os municípios, incluindo a possibilidade de ampliação de aspectos relevantes para a gestão dos serviços como os mecanismos de participação social. Os novos planos, diferente dos anteriores, tendem a ser instrumentos de planejamento participativo que podem contribuir para o desenvolvimento sustentável no município e região (LIMA NETO \& SANTOS, 2012).

Apesar dos benefícios enumerados e da exigência legal, as experiências de elaboração de planos de saneamento são pouco numerosas, cabendo questionar quais dificuldades os municípios têm enfrentado e indicar iniciativas que contribuam para reduzir esses impasses. É importante também compreender a motivação e o papel dos planos de saneamento, investigando se eles tendem a ser elaborados apenas com vistas ao cumprimento da legislação ou por convicção dos reais benefícios que podem ser alcançados ao utilizá-los como ferramenta de gestão. O presente trabalho busca levantar e discutir as principais dificuldades e motivações vivenciadas diante da necessidade de elaboração do Plano Municipal de Saneamento Básico, identificando os avanços necessários para a adoção efetiva do planejamento e para que a legislação se converta em reais melhorias para o setor.

\section{Metodologia}

A pesquisa tem como objeto de estudo 15 municípios localizados na Zona da Mata de Minas Gerais. Utilizou-se metodologia qualitativa de coleta e análise de dados com a realização de entrevistas semiestruturadas 
com gestores de serviços de saneamento. A identificação e o contato inicial com os municípios ocorreram por meio do Consórcio Intermunicipal de Saneamento da Zona da Mata (CISAB) ${ }^{1}$.

Dezoito municípios solicitaram ajuda do CISAB na preparação do processo de elaboração do plano de saneamento, requerendo financiamento junto aos órgãos públicos. Foram entrevistados representantes de 15 autarquias que prestam serviço de abastecimento de água e esgotamento sanitário, em visita agendada ao município ou em assembleia do consórcio ${ }^{2}$. A entrevista contou com seis perguntas relativas ao tipo de planejamento desenvolvido, às dificuldades encontradas para iniciar a elaboração do plano de saneamento e à motivação e expectativa de mudança a partir da sua implementação.

A análise de dados iniciou com a transcrição das entrevistas gravadas e posterior exploração do conteúdo das falas, utilizando-se o Discurso do Sujeito Coletivo (DSC). Trata-se de uma técnica que trabalha com dados qualitativos de natureza verbal (obtidos por meio de fontes como entrevistas, depoimentos, artigos de jornal ou matérias em revistas semanais). Trata-se de agrupar partes das diversas falas para formar um discurso único, no qual cada entrevistado se reconhece enquanto constituinte do todo. Buscou-se identificar ideias centrais, palavras-chave e ancoragem e foram selecionadas expressões-chave das respostas individuais, que são trechos mais significativos, correspondentes às ideias centrais que sintetizam o conteúdo discursivo manifestado (LEFÈVRE \& LEFÈVRE, 2005). Com esse material, construíram-se discursos-síntese na primeira pessoa do singular, nos quais o pensamento de um grupo ou coletividade aparece como um discurso individual (LEFÈVRE et al., 2003) e, havendo discursos diferentes, complementares ou antagônicos, os mesmos são apresentados. As falas construídas a partir do DSC são apresentadas entre aspas ao longo do texto.

\section{Resultados e Discussão}

Os entrevistados ocupam cargos diversificados nos órgãos de saneamento, têm diferentes formações e diversificada experiência profissional no setor (Tabela 1). A maior parte dos entrevistados é representante da autarquia municipal responsável pelos serviços de abastecimento água e esgotamento sanitário e, em quase todos os municípios, os serviços de limpeza urbana e drenagem são de responsabilidade da administração direta.

Os entrevistados atuam nos órgãos de saneamento ${ }^{3}$, sendo 11 deles diretores das autarquias e os demais, representantes indicados pelo dire-

${ }^{1} \mathrm{O}$ CISAB foi criado em 2008 com o objetivo de auxiliar na capacitação técnica de funcionários do saneamento dos 22 municípios consorciados para executarem suas tarefas e aperfeiçoarem a gestão dos serviços.

${ }^{2}$ Em assembleia do CISAB realizada em Viçosa, em 15/12/2010, foram entrevistados representantes dos municípios de Carangola, Fervedouro, Lajinha, Lima Duarte, Manhumirim, Recreio, Reduto e Vermelho Novo

${ }^{3}$ Exceto no município de Jequeri, onde a entrevista foi realizada com o Secretário de Meio Ambiente.

${ }^{4}$ Fundo de Participação dos Municípios.

${ }^{5}$ Imposto sobre Circulação de Mercadorias e Serviços. tor. O grau de instrução dos entrevistados varia de ensino médio, passando por qualificações de nível técnico, até formação de nível superior nas áreas de arquitetura, direito, administração e história. Os participantes da pesquisa têm entre 2 e 29 anos de experiência no setor de saneamento.

\section{Entraves ao planejamento municipal do saneamento básico}

As perguntas feitas aos gestores questionaram a respeito das dificuldades que têm impedido o início da elaboração do Plano Municipal de Saneamento Básico. A discussão a seguir aborda diferentes aspectos e está organizada segundo o grau de importância dos problemas que foram enumerados

A dificuldade financeira prevaleceu na opinião dos entrevistados. No entanto, dois deles não a colocaram como principal entrave ao início da elaboração do plano, por considerarem que "a questão financeira é um problema, mas a autarquia tem arrecadação suficiente para custear o plano, desde que haja vontade da gestão pública e planejamento". Neste caso, os entrevistados entendem que, havendo uma decisão clara de investir no planejamento por parte dos gestores, a autarquia de saneamento pode custear a elaboração do plano diluindo os gastos, sendo necessário "ter um cronograma de trabalho e reduzir investimento no período, o que seria compensado pelos resultados do plano inclusive no que se refere à obtenção de recursos". Os valores que deixam de ser investidos na melhoria dos serviços durante alguns meses podem ser recuperados, pois o plano elaborado abre oportunidades para obtenção de recursos para o setor de saneamento.

A maior parte dos prestadores de serviços de saneamento municipais tem enfrentado situações de carência de recursos: "o recurso financeiro é uma dificuldade porque o SAAE e o município não têm dinheiro, é pequeno e tem poucos habitantes". Os municípios em si também carecem de recursos para o plano, uma vez que a "maioria das prefeituras trabalha com déficit, não tem arrecadação suficiente e depende do repasse do $\mathrm{FPM}^{4}, \mathrm{ICMS}^{5}$ e convênios". A manutenção do sistema e o atendimento à população manifestam-se como dificuldades, havendo impossibilidade de destinação de recursos para a elaboração do plano, sendo possível para o município "arcar com uma contrapartida, mas não com o recurso para o plano todo".

Do total de entrevistados, 13 apontam a indisponibilidade de recurso financeiro como a maior dificuldade a ser vencida para alavancar o planejamento do saneamento no município. "A falta do recurso é a primeira dificuldade". Atribui-se um elevado custo ao desenvolvimento do planejamento, não sendo suficiente o recurso disponível,

principalmente porque a elaboração do plano é muito cara. A questão financeira resume todas as dificuldades, as outras podem ser resolvidas, mas sem o recurso não tem jeito. 
Tabela 1 - Caracterização dos entrevistados segundo município.

\begin{tabular}{|c|c|c|c|c|c|}
\hline Município & $\begin{array}{l}\text { Órgão e componentes do } \\
\text { saneamento }\end{array}$ & $\begin{array}{l}\text { População do } \\
\text { município* }\end{array}$ & Cargo/função & $\begin{array}{l}\text { Experiência no } \\
\text { setor (anos) }\end{array}$ & Formação \\
\hline Abre Campo & SAAE - Água & 13.304 & Diretor & 14 & História \\
\hline Carangola & $\begin{array}{c}\text { SEMASA } \\
\text { Água, Esgoto e Resíduos }\end{array}$ & 32.293 & Assessor Administrativo & 28 & Técnico em contabilidade \\
\hline Fervedouro & $\begin{array}{c}\text { SAAE } \\
\text { Água e Esgoto }\end{array}$ & 10.351 & Diretor & 15 & Técnico em contabilidade \\
\hline Jequeri & $\begin{array}{c}\text { SAAE } \\
\text { Água e Esgoto }\end{array}$ & 12.843 & $\begin{array}{l}\text { Secretário de Meio Am- } \\
\text { biente }\end{array}$ & 6 & Ensino Médio \\
\hline Lajinha & $\begin{array}{c}\text { SAAE } \\
\text { Água e Esgoto }\end{array}$ & 19.582 & Diretor & 6 & Administração \\
\hline Lima Duarte & $\begin{array}{c}\text { SAAE } \\
\text { Água e Esgoto }\end{array}$ & 16.092 & Diretor & 6 & Não informado \\
\hline Manhumirim & $\begin{array}{c}\text { SAAE } \\
\text { Água e Esgoto }\end{array}$ & 21.251 & Diretor de Expansão & 2 & Ensino Fundamental \\
\hline Muriaé & $\begin{array}{c}\text { DEMSUR } \\
\text { Água, Esgoto, Resíduos e } \\
\text { Drenagem }\end{array}$ & 99.949 & Diretora & 18 & Arquitetura \\
\hline Ponte Nova & $\begin{array}{c}\text { DMAES } \\
\text { Água e Esgoto }\end{array}$ & 55.958 & $\begin{array}{c}\text { Assessor de Orçamento e } \\
\text { Programa }\end{array}$ & 18 & Direito \\
\hline Raul Soares & $\begin{array}{c}\text { SAAE } \\
\text { Água e Esgoto }\end{array}$ & 23.803 & Diretor & 29 & Direito \\
\hline Recreio & $\begin{array}{c}\text { SAAE } \\
\text { Água e Esgoto }\end{array}$ & 10.295 & Diretora & 2 & Administração \\
\hline Reduto & $\begin{array}{c}\text { SAAE } \\
\text { Água e Esgoto }\end{array}$ & 6.449 & Diretor & 6 & Direito \\
\hline Senador Firmino & $\begin{array}{c}\text { SAAE } \\
\text { Água e Esgoto }\end{array}$ & 7.230 & Diretor & 29 & Ensino Médio \\
\hline Senhora de Oliveira & $\begin{array}{c}\text { SAAE } \\
\text { Água e Esgoto }\end{array}$ & 5.600 & Diretor & 6 & Não informado \\
\hline Vermelho Novo & $\begin{array}{c}\text { SAAE } \\
\text { Água e Esgoto }\end{array}$ & 4.689 & Diretor & 13 & Administração \\
\hline
\end{tabular}

Fonte: dados coletados em trabalho de campo.

*Dados do Censo Demográfico 2010. Disponível em: http://www.ibge.gov.br/home/estatistica/populacao/censo2010/default uf.shtm

SAAE: Serviço Autônomo de Água e Esgoto; SEMASA: Serviço Municipal de Saneamento Básico e Infraestrutura; DEMSUR: Departamento Municipal de Saneamento Urbano;

DMAES: Departamento Municipal de Água, Esgoto e Saneamento.

Dentre os entrevistados que apontam a dificuldade financeira como o principal fator limitante para elaborar o plano, as opiniões se dividem quanto à relevância desse aspecto em relação aos demais problemas. Alguns consideram que há outros problemas importantes que dificultam a elaboração do plano, enquanto, para outros, o "principal e talvez o único problema é o recurso, ele é fundamental e representa 99\%". Sendo assim, com a obtenção de recurso, os outros fatores limitantes tornam-se pouco importantes e podem ser facilmente resolvidos, uma vez que "tendo o dinheiro não há mais dificuldade, tudo se resolve, monta-se a equipe, contratam-se os profissionais etc". Aliada à disponibilidade de recursos, considera-se que a elaboração do plano está relacionada à mobilização e empenho dos envolvidos.

Ao se deparar com a dificuldade financeira, consensualmente apontada como um dos principais entraves a serem superados, reforça-se a importância de adotar uma estratégia de planejamento. Ferreira (1981) e Matus (1989) consideram o planejamento como uma necessidade diante da escassez de recursos, a fim de que sejam obtidos os melhores resultados possíveis com o uso dos limitados recursos disponíveis. Sendo assim, a elaboração do plano de saneamento, mesmo demandando um investimento financeiro inicial, pode ser apontada como uma possível solução para a cotidiana escassez de recursos vivenciada pelo setor de saneamento nos municípios.
Os entrevistados apontaram também outras dificuldades significativas, relacionadas à qualificação técnica e profissional, vontade política dos gestores, disponibilidade no quadro de funcionários, aspectos metodológicos, integração entre as áreas que compõem o setor de saneamento em âmbito municipal e outros fatores que podem ser identificados no decorrer da elaboração do plano.

No que diz respeito à capacidade técnica do município e dos órgãos de saneamento com relação aos profissionais disponíveis para participar da elaboração do plano, percebe-se uma dificuldade comum, não sendo possível concluir o planejamento sem participação de pessoas contratadas para exercer ao menos algumas funções. Apenas dois entrevistados informaram não haver disponibilidade de funcionários locais para contribuir tecnicamente na elaboração do plano, uma vez que "para elaborar o plano teria que contratar outras pessoas, pois nós não temos condição; a própria prefeitura contrata porque não tem técnicos". No entanto, verifica-se que é pequena a dependência total da contratação de profissionais para compor a equipe técnica.

Os entrevistados identificam que existe dificuldade quanto à disponibilidade de profissionais nos municípios e à sua qualificação técnica para desenvolver o planejamento; sendo assim, a "autarquia não 
teria condição de elaborar o plano", havendo poucos funcionários e baixa capacidade técnica. "Nossa equipe tem número insuficiente de servidores e os funcionários têm pouca capacidade técnica. Temos problema inclusive com encanadores, pedreiros etc". Trata-se de uma dificuldade comum entre os municípios, sinalizando um importante problema que demanda a contratação de profissionais para auxiliar no desenvolvimento do planejamento municipal.

Estamos tentando elaborar o plano, precisamos de profissionais para apoiar, pois uma grande dificuldade é o recurso humano; numa cidade pequena é difícil encontrar esses profissionais.

Cabe destacar que a participação no consórcio de saneamento é avaliada de maneira positiva, pois consideram que "o apoio do CISAB é importante para vencer essa limitação de profissionais".

Apesar da dificuldade apontada, existe otimismo quanto à identificação de alguns profissionais dentro do município com potencial para contribuir ou auxiliar no desenvolvimento do plano, compondo parte da equipe técnica.

O plano não é só responsabilidade do setor de saneamento, mas do município e assim profissionais competentes da cidade podem participar, embora não tenhamos todos os que são exigidos pela lei.

Sendo assim, a necessidade de contratação de outros profissionais existe, porém é reduzida com a participação de pessoas do município. "Realizando um trabalho conjunto entre o SAAE e equipes da prefeitura (área da saúde, agricultura, obras etc.) é possível montar uma equipe municipal, não necessitando contratar todos os profissionais externos".

Ainda com a composição de uma equipe de trabalho local, a necessidade de contratação de profissionais existe; "por causa das deficiências do município e da baixa capacidade técnica, é necessário contratar pessoas capacitadas, experientes e com conhecimento na área para dar apoio". A demanda de profissionais torna-se ainda mais acentuada para os cargos de liderança e coordenação da elaboração do plano.

Os profissionais competentes disponíveis no município não têm experiência em planejamento por ser algo novo; precisa de alguém experiente no assunto para coordenar o trabalho e capacitar os envolvidos.

Os profissionais do município disponíveis para se envolverem na elaboração do plano não têm conhecimentos técnicos específicos nem experiência em trabalhar com planejamento, sendo importante realizar reuniões e cursos de capacitação.

Dentre os entrevistados, dois informaram desconhecer as metodologias possíveis para elaboração do Plano Municipal de Saneamento Básico, sem informações no que se refere a como iniciar o planejamento e as etapas ou procedimentos a serem seguidos, como pode ser percebido no discurso a seguir:

haveria dificuldade de saber como fazer, por onde começar e as etapas para seguir; teria que fazer um estudo pra usar uma metodologia. Haveria dificuldade para compilar as informações, fazer o plano, montar... A gente não tem experiência pra isso.

A maioria dos gestores dos municípios considera que, mesmo não tendo conhecimentos específicos sobre o assunto, a questão metodológica não se constitui como uma grande dificuldade, sendo facilmente resolvida diante da disponibilidade de recurso, vontade política e dedicação dos envolvidos. "A metodologia de elaborar o plano não seria um problema, pois tendo comprometimento e vontade é só buscar cumprir o que a lei pede e recorrer aos manuais existentes". Os entrevistados sabem sobre a existência de manuais e guias de orientação para a elaboração de planos de saneamento, cabendo à equipe elaboradora buscar aprender e seguir as propostas e definições contidas nesses documentos. "Os manuais (termos de referência da FUNASA ou diretrizes do Ministério das Cidades) são muito bons e vão orientar por onde começar e os passos para seguir e não haverá dificuldade".

Os termos de referência citados pelos entrevistados são documentos originados de esforços normativos governamentais que visam aprofundar os marcos metodológicos e estabelecer orientações para que os municípios avancem na elaboração de seus planos. A Fundação Nacional de Saúde elaborou uma norma técnica a ser seguida por municípios aos quais concederem recursos (BRASIL, 2010) e o Ministério das Cidades tem elaborado diversos documentos a fim de disseminar a prática do planejamento do setor de saneamento (BRASIL, 2005; 2006; 2009; 2010). Embora não tenha sido comentado pelos entrevistados, cabe destacar a possibilidade de incrementar o desenvolvimento do plano de saneamento com metodologias que permitam avançar no que se refere às perspectivas para o futuro do setor, como o planejamento estratégico situacional (MATUS, 1989; HUERTAS, 1996) ou o planejamento através do uso de cenários prospectivos (SCHWARTZ, 1996; GODET \& DURANCE, 2009).

A integração do serviço de abastecimento de água e esgotamento sanitário com os demais componentes do saneamento (gestão de resíduos sólidos e drenagem de águas pluviais) é vista de maneiras diferentes. Reconhecendo-se o distanciamento entre os quatro componentes, alguns entrevistados consideram que esse aspecto dificulta a elaboração conjunta do plano.

A integração dos setores é horrível, quase inviabiliza fazer o plano, porque eles não se falam, não trocam informações, a falta de integração é o maior entrave para elaborar um plano, não existe integração. 
No entanto, grande parte dos entrevistados considera que a distância pode ser superada, tornando-se um motivo de diálogo entre os setores, uma vez que "a dificuldade de integração existe, mas é uma questão de começar a conversar e aproximar, explicar a importância do plano etc.".

O trabalho conjunto entre os representantes dos componentes do saneamento é visto por alguns entrevistados como um potencial e um fator positivo para a elaboração do plano, propiciando que sejam vencidas as diferenças e possíveis dificuldades de relacionamento entre as referidas áreas.

Em municípios pequenos o trabalho conjunto é positivo e potencializa a elaboração do plano, pois o SAAE sozinho não consegue. Mesmo não havendo integração com os setores de drenagem e resíduos, é uma oportunidade de diálogo. Com o coordenador explicando o que deve ser feito e a função de cada setor, haverá uma boa integração.

Identificam-se ainda municípios que têm realizado um trabalho de maneira integrada entre as áreas do saneamento ao afirmarem: "nós trabalhamos bem com os outros setores, isso pode ajudar". As iniciativas de integração são vistas como motivação para que a elaboração do plano seja bem sucedida. Esse diálogo previamente existente pode facilitar o apoio entre as áreas do setor de saneamento, agilizando os procedimentos no processo de planejamento.

A integração é um aspecto positivo, só vai funcionar se for integrado. Há um bom diálogo entre os setores porque a gente trabalha em conjunto, um completa o outro. Em questão de relacionamento dos setores não temos problemas.

A "vontade política é importante..." Ela foi citada como um fator que pode alavancar a elaboração do plano, sendo possível também estar associada ao seu entrave, uma vez que, em muitos casos, "o que falta é a vontade de fazer o plano". Sendo assim, é preciso saber lidar com esse aspecto, limitando seus efeitos negativos quando possível.

Seria um grande entrave a administração não ver que é viável. A pior coisa que pode retardar a elaboração do plano é a questão política, pois ela nem sempre quer atender aos anseios do povo, às vezes busca interesses pessoais

Os gestores entrevistados consideram ainda que, ao se iniciar a elaboração do Plano Municipal de Saneamento Básico, outras dificuldades que não foram mencionadas poderão surgir. "Fatores de dificuldade têm vários. Começando a elaborar o plano se veem os problemas, vão surgir outros, mas nada que limite". Ainda assim, haveria grande possibilidade de superação e inclusive um ansioso desejo de que essas dificuldades apareçam, sinalizando que o processo de planejamento está em curso. "Eu não tenho problemas com o plano, eu gostaria de ter. Os problemas vão começar quando estivermos fazendo o plano".

\section{Planejamento Municipal: plano por obrigação ou por convicção?}

O tipo de planejamento que vem sendo realizado nos serviços de saneamento pode indicar a motivação para o uso desse instrumento de gestão: se está voltada apenas para o cumprimento da exigência da legislação ou se está pautada na consciência da importância das ações planejadas e dos benefícios na melhoria dos serviços. Dentre os 15 municípios investigados, 8 realizam algum tipo de planejamento (2 elaboram planos de longo, médio e curto prazos, outros 2 desenvolvem planejamento a cada 4 anos e 4 municípios realizam planejamento de curto prazo ou anual). Os demais municípios não realizam nenhum tipo de planejamento, trabalhando com ações pontuais diante das demandas do dia a dia.

Como defende Matus (HUERTAS, 1996), a adoção do planejamento focaliza a realização de ações por meio de iniciativas planejadas, a fim de evitar ações improvisadas, que têm menor potencial de sucesso. Dessa maneira, é possível posicionar-se em preparação para as mudanças futuras e promovendo-as conforme desejado (GODET \& DURANCE, 2009). Ademais, a falta de planejamento no âmbito municipal contribui para o desencadeamento de descontinuidades e fragmentação das ações voltadas para o setor, colaborando muitas vezes para o desperdício de recursos e ineficiência dos serviços (BRASIL, 2005).

A importância da elaboração do plano de saneamento foi percebida com unanimidade pelos gestores, que reconhecem a necessidade de desenvolver ações planejadas, pois "quando não temos plano, queremos desenvolver muita coisa e acabamos não fazendo nada, ficamos dando cabeçada". Os entrevistados entendem que, como apontam Heller e Nascimento (2005), o planejamento no setor de saneamento é uma necessidade ainda não completamente satisfeita, sendo necessário esforço nesse sentido. Os municípios têm manifestado empenho diante da demanda de realizar o planejamento municipal do saneamento. No entanto, têm se deparado com dificuldades significativas, as quais têm buscado resolver A participação no consórcio de saneamento é importante para motivação dos gestores dos municípios investigados, como tem sido verificado em diversas iniciativas do setor de saneamento (SILVEIRA \& PHILIPPI, 2008).

A importância de planejar o setor está em alcançar os objetivos de conhecer a real necessidade da população, aumentar o envolvimento e participação social, avançar na gestão e melhorar a qualidade dos serviços prestados. Os gestores têm expectativas positivas quanto à elaboração dos planos de saneamento, permitindo trabalhar com alguma previsibilidade, uma vez que "tendo um plano as coisas ficam mais fáceis, passamos a ter uma direção, prazos definidos e metas a cumprir, o que facilita o trabalho".

A expectativa quanto à melhoria dos serviços aparece com grande relevância ao afirmarem: "com a elaboração do plano conseguiremos melhorar o serviço e o atendimento à população, prestando um serviço de melhor qualidade". Há também uma preocupação específica com o esgotamento sanitário, considerado alvo prioritário de investimento, relacionado diretamente à saúde da população, na medida em que a 
inadequada disposição constitui-se como uma séria ameaça que afeta a qualidade ambiental (RIBEIRO, 2004).

O esgotamento é uma das primeiras metas, poderia melhorar com o plano; não temos tratamento de esgoto, só a coleta, ele sai das casas, mas é jogado no córrego e em alguns lugares tem esgoto a céu aberto.

A participação social, que pode ocorrer em diferentes níveis (BORDENAVE, 1995; BRASIL, 2006), tem sido entendida como uma tendência positiva ao tornar o desenvolvimento urbano mais participativo (FARMER et al., 2006). A esse respeito, os gestores abordam três pontos de vista, considerando que o plano promoverá um avanço na participação social: a) haverá maior participação da população nas atividades e "a partir do momento em que a comunidade participa fica mais fácil trabalhar"; b) a sociedade também terá maior reconhecimento pelo trabalho desenvolvido pelos órgãos de saneamento, que assim obterá "mais credibilidade dos moradores" ao ver as atividades sendo realizadas de maneira adequada e seguindo um planejamento e c) ao participar do plano, as pessoas teriam mais consciência e poderiam colaborar com as ações dos órgãos de saneamento: "ajudaria muito, a população ter consciência do que é a parte dela, o que ela pode fazer para melhorar e não prejudicar os serviços". Além disso, a partir da Lei no 11.445 e da demanda para elaboração de planos municipais de saneamento, abre-se para o potencial de vir a se constituir em importante meio de envolvimento da sociedade na problemática do setor (HELLER et al., 2007). O uso de uma metodologia participativa no planejamento pode abrir caminho para a atuação efetiva da população, estabelecendo-se diálogos e mecanismos de participação, aspectos importantes para alcançar um impacto significativo na saúde a partir da adoção de uma solução tecnológica (HELLER \& NASCIMENTO, 2005). A participação social vem se efetivando por meio de vários instrumentos e tem estado presente nos novos modelos de planejamento (FARMER et al., 2006).

O planejamento facilita a obtenção de recursos e a continuidade das ações. Entende-se que o plano de saneamento "é importante pra ter acesso aos recursos, pra financiar as obras no município", já que, para obter acesso às verbas, é necessário ter um planejamento e credibilidade, facilitando a identificação de possíveis fontes de financiamento (BRASIL, 2007). Diante do relato de situações de descontinuidade das atividades associadas à mudança do gestor do município, considera-se que plano de saneamento é "um documento formalizado para dar sequência ao trabalho, porque a continuidade do plano precisa ser seguida independente do gestor do município". Segundo Yévenes-Subiatre (2010), o planejamento no município tem uma atuação positiva na gestão dos serviços, permitindo alcançar maiores benefícios para a população. Outros fatores, além de uma correta abordagem tecnológica, se fazem necessários para uma adequada provisão dos serviços de saneamento, como a atuação do Estado na organização institucional e em sua implementação (HELLER \& CASTRO, 2007).

Diante das manifestações a respeito das melhorias esperadas com a elaboração do plano de saneamento, verifica-se empenho da esfera municipal no sentido de atender a proposta da legislação nacional de planejamento do saneamento como uma iniciativa que promoverá benefícios ao setor. Dessa maneira, embora a conclusão dos planos esteja longe de sua concretização, os esforços voltados para o planejamento estão sendo realizados pelos gestores com convicção, não tendendo a ser um plano meramente realizado por obrigação em atendimento à exigência legal. Os desafios dos municípios são muitos e sua identificação é apenas o passo inicial da trajetória a ser percorrida para que eles sejam superados, sendo necessário ainda adotar várias ações que permitam apoiar os gestores e autarquias municipais.

\section{Conclusão}

Tendo sido levantadas e discutidas as dificuldades vivenciadas pelos gestores do saneamento em municípios de pequeno porte, ao se depararem com a demanda de realização do Plano Municipal de Saneamento Básico, espera-se que a discussão contribua para tornar possível a implementação das iniciativas necessárias para superar os obstáculos apresentados. As principais dificuldades identificadas para a elaboração do plano de saneamento são a indisponibilidade de recursos financeiros e a limitação quanto à qualificação profissional e capacidade técnica municipal. No entanto, ao vencer o primeiro obstáculo, a qualificação profissional pode ser parcialmente resolvida mediante realização de capacitação e contratação de profissionais, o que pode igualmente superar as dificuldades metodológicas. Questões como integração de órgãos das áreas que compõem o saneamento e vontade política também foram apontadas como obstáculos ao planejamento.

Para que o planejamento do saneamento possa avançar, identificam-se demandas importantes. A medida mais urgente é a ampliação da liberação de recursos por parte dos órgãos públicos para a elaboração do plano e a facilitação do acesso dos municípios, pois se verifica impossibilidade dos órgãos de saneamento em arcar com os custos do planejamento. As principais fontes de recursos a serem consideradas nessa ampliação são a Fundação Nacional de Saúde e o Ministério das Cidades.

A insuficiência de profissionais e a baixa capacidade técnica podem ser minimizadas com contratação de profissionais quando da obtenção de recurso necessário. O desenvolvimento de cursos de capacitação possibilitaria qualificação específica para elaborar o plano de saneamento, além se permitir o conhecimento sobre procedimentos metodológicos. Esse tipo de iniciativa pode ser facilitado pela participação em consórcios públicos de saneamento, como é o caso dos municípios investigados. A realização de campanhas de sensibilização sobre o planejamento do saneamento pode contribuir para mobilizar os envolvidos.

Apesar das dificuldades inerentes ao processo de elaboração dos planos de saneamento, ele é visto com otimismo e significativa motivação, o que pôde ser identificado nas entrevistas com os gestores. Ainda que não se possam tecer afirmações sobre a efetividade dos planos quando de sua elaboração, percebe-se que eles não terão seu desenvolvimento, conduzido apenas pela motivação do cumprimento à demanda da legislação, mas eles tendem a ser elaborados segundo os benefícios esperados, adotando-se o planejamento como convicção dos seus reais benefícios. 


\section{Referências}

BORDENAVE, J.E.D. (1995) O que é participação? São Paulo: Brasiliense.

BRASIL (2004) Avaliação de Impacto na Saúde das Ações de Saneamento: marco conceitual e estratégia metodológica. Brasília: Ministério da Saúde, OPAS/OMS.

BRASIL (2005) Políica e Plano Municipal de Saneamento Ambiental: experiências e recomendações. Brasília: Ministério das Cidades/OPAS.

BRASIL (2006) Guia para a Elaboração de Planos Municipais de Saneamento. Brasília: Ministério das Cidades.

BRASIL (2007) Lei de Saneamento Básico (Lei no 11.445). Brasília.

BRASIL (2009) Resolução recomendada $n^{\circ}$ 75: Estabelece orientações relativas à Política de Saneamento Básico e ao conteúdo mínimo dos Planos de Saneamento Básico. Brasília: Ministério das Cidades/Conselho das Cidades.

BRASIL (2010) Termo de Referência para Elaboração de Planos Municipais de Saneamento Básico e Procedimentos Relativos ao Convênio de Cooperação Técnica e Financeira da Fundação Nacional de Saúde-FUNASA/MS. Brasília: Ministério da Saúde/Fundação Nacional da Saúde (FUNASA).

CLASEN, T.F. \& CAIRNCROSS, S. (2004) Household Water Management: refining the dominant paradigm. Tropical Medicine and International Health, v. 9, n. 2, p. 187-191.

EZZATI, M.; UTZINGER, J.; CAIRNCROSS, S.; COHEN, A. J.; SINGER, B.H. (2005) Environmental Risks in the Developing World: exposure indicators for evaluating interventions, programmes, and policies. Epidemiological Community Health, v. 59, p. 15-22.

FARMER, P.; FROJMOVIC, M.; HAGUE, C.; HARRIDGE, C.; NARANG, S.; SHISHIDO, R.; SIEGEL, D.; TAYLOR, P.; VOGELIJ, J. (2006) Reinventing Planning: a new governance paradigm for managing human settlements. Disponível em: <http://www.globalplannersnetwork.org/pdf/ reinventingplanningenglish.pdf > . Acesso em: 3 jun. 2011.

FERREIRA, F.W. (1981) Planejamento Sim e Não. 2. ed. Rio de Janeiro: Paz e Terra.

FRIEDMANN, J. (1987) Planning in the public domain: from knowledge to action. Princeton: Princeton University Press.

FRIEDMANN, J. (1992) Planificación para el Siglo XXI: el dasafio del posmodernismo. EURE, v. XVIII, n. 55, p. 79-89.

GALVÃO JÚNIOR, A.C.; SOBRINHO, G.B.; SILVA, A.C. (2012) Painel de Indicadores para Planos de Sameamento Básico. In: PHILIPPI JÚNIOR, A. \& GALVÃO JÚNIOR, A.C. (Ed.). Gestão do Saneamento Básico: abastecimento de água e esgotamento sanitário. Barueri: Manole. p. 1040-1068.

GODET, M. \& DURANCE, P. (2009) La prospectiva estratégica para las empresas y los territorios. Paris: LIPSOR.
HELLER, L. \& CASTRO, J.E. (2007) Política Pública de Saneamento: apontamentos teórico-conceituais. Engenharia Sanitária e Ambiental, v. 12 , n. 3, p. 284-295

HELLER, L. \& NASCIMENTO, N.O. (2005) Pesquisa e Desenvolvimento na Área de Saneamento no Brasil: necessidades e tendências. Engenharia Sanitária e Ambiental, v. 10, n. 1, p. 24-35

HELLER, L.; REZENDE, S.; HELLER, P. (2007) Participação e Controle Social em Saneamento Básico: aspectos teórico-conceituais. In: GALVÃO JÚNIOR, A.; XIMENES, M. (Eds.). Regulação: controle social da prestação dos serviços de água e esgoto. Fortaleza: ABAR p. 37-68.

HUERTAS, F. (1996) O método PES: entrevista com Matus. Tradução de Giselda Sauveur. São Paulo: FUNDAP.

KLOSTERMAN, R.E. (2003) Arguments for and against planning. In: CAMPBELL, S. \& FAINSTEIN, S.S. (Eds.). Readings in Planning Theory Oxford: Blackwell Publishing. p. 86-101.

LEFÈVRE, A.M.C.; CRESTANA, M.F.; CORNETTA, V.K. (2003) A utilização da metododologia do discurso do sujeito coletivo na avaliação qualitativa dos cursos de especialização "Capacitação e Desenvolvimento de Recursos Humanos em Saúde-CADRHU”. Saúde e Sociedade, v. 12, n. 2, p. 68-75.

LEFÈVRE, F. \& LEFÈVRE, A.M.C. (2005) O Discurso do Sujeito Coletivo: um novo enfoque em pesquisa qualitativa (desdobramentos). Caxias do Sul: EDUCS.

LIMA NETO, I.E. \& SANTOS, A.B.D. (2012) Planos de Saneamento Básico. In: PHILIPPI JÚNIOR, A.; GALVÃO JÚNIOR, A.C. (Orgs.). Gestão do Saneamento Básico: abastecimento de água e esgotamento sanitário. Barueri: Manole. p. 57-79.

MATUS, C. (1989) Fundamentos da Planificação Situacional. In: URIBE RIVERA, F.J. Planejamento e Programação em Saúde: em enfoque estratégico. São Paulo: Cortez. p. 107-123.

RIBEIRO, H. (2004) Saúde Pública e Meio Ambiente: evolução do conhecimento e da prática, alguns aspectos éticos. Saúde e Sociedade, v. 13, n. 1, p. 70-80.

SCHWARTZ, P. (1996) The Art of the Long View: planning for the future in an uncertain world. New York: Currency.

SILVEIRA, R.C.E.D. \& PHILIPPI, L.S. (2008) Consórcios Públicos: uma alternativa viável para a gestão regionalizada de resíduos sólidos urbanos. Redes, v. 13, n. 1, p. 205-224

YÉVENES-SUBIATRE, A. (2010) Prospectiva y estrategia en el escenario contemporáneo. Latin American Journal of International Affairs, v. 2, n. 3, p. 90-106. 